\title{
Red, Green and Blue Silicate Phosphor Thin Films by Pulsed Laser Deposition
}

\author{
X. W. Sun and H. S. Kwok \\ Center for Display Research \\ Department of Electrical and Electronic Engineering \\ The Hong Kong University of Science and Technology \\ Clear Water Bay, Kowloon, Hong Kong
}

\begin{abstract}
$\underline{\text { Abstract }}$
Three kinds of silicate phosphor thin films, emitting in the red-green-blue (RGB) primary colors, were fabricated by pulsed laser deposition: manganese and lead doped calcium silicate $\left(\mathrm{CaSiO}_{3}: \mathrm{MnPb}\right)$ for red color, manganese doped zinc silicate $\left(\mathrm{Zn}_{2} \mathrm{SiO}_{4}: \mathrm{Mn}\right)$ for green color, and cerium doped yttrium silicate $\left(\mathrm{Y}_{2} \mathrm{SiO}_{5}: \mathrm{Ce}\right)$ for blue color. A good correlation was found between photoluminescence intensity and film crystallinity and surface morphology.
\end{abstract}

\section{$\underline{\text { Introduction }}$}

Phosphors are widely used in emissive displays. However, all currently used phosphors still need considerable improvement such as in lower current saturation, high efficiency, and better chromaticity [1]. Oxide phosphor (including silicate phosphor) is more chemically stable than sulfide phosphors under high Coulomb loading. As a matter of fact, silicate phosphors such as $\mathrm{Zn}_{2} \mathrm{SiO}_{4}$ :Mn have been used in CRTs. Electroluminescence (EL) device have also been made from these same silicate [2]. In all the display applications, thin film phosphor is preferred over powder phosphors due to its high contrast ratio, high ambient visibility, high image resolution and good heat resistance [3].

Pulsed laser deposition (PLD) technique, which has been quite successful in depositing complex superconducting oxide thin films, provides a unique process for stoichiometric evaporation of target materials [4]. Doped silicate phosphor is a complex compound system, which generally consisted of four or more kinds of elements. Such silicate phosphors are good candidates for PLD studies.

In the past, PLD has been employed for the growth of phosphor thin films such as $\mathrm{ZnS}, \mathrm{SrS}, \mathrm{ZnO}$, YAGG, $\mathrm{Y}_{2} \mathrm{O}_{3}:$ Eu [5-9]. It has not been applied to silicate phorsphors. RE-doped yttrium silicate phosphor has also been deposited by sputtering [10]. In here, we report our work of PLD deposited RGB silicate phosphors doped with different transition and rare-earth metals in their thin film form. We shall also correlate their structural, surface morphology to the luminescent properties.

\section{Experimental}

Commercial phosphor powders from Phosphor Technology $\left(\mathrm{CaSiO}_{3}: \mathrm{MnPb}, \mathrm{Zn}_{2} \mathrm{SiO}_{4}: \mathrm{Mn}, \mathrm{Y}_{2} \mathrm{SiO}_{5}: \mathrm{Ce}\right)$ were cold-pressed into 1 "-disks, and sintered at $1000^{\circ} \mathrm{C}$ for 5 hours to make hard ceramic targets for laser ablation. The pulsed laser deposition experiments were performed on these targets with a 193nm Lambda Physik ArF excimer laser. The substrates used for the deposition were either (100) bare silicon or silicon substrates with a thermally grown 1000A silicon dioxide on top.

All the films were deposited at a substrate temperature of $300^{\circ} \mathrm{C}$. Annealing were performed on these samples in air at temperatures ranging from $400^{\circ} \mathrm{C}$ to $1200^{\circ} \mathrm{C}$. All as-grown and annealed films were characterized by X-ray photoelectron spectroscopy (XPS), X-ray diffraction (XRD), scanning electron microscopy (SEM), atomic force microscopy (AFM), and photoluminescence (PL) measurements.

\section{Results and discussion}

Table 1. Chemical composition (\%) of $\mathrm{CaSiO}_{3}: \mathrm{MnPb}$ target, as-grown and $1000^{\circ} \mathrm{C}$ annealed films.

\begin{tabular}{|l|l|l|l|l|l|l|}
\hline & $\mathrm{C}$ & $\mathrm{O}$ & $\mathrm{Si}$ & $\mathrm{Ca}$ & $\mathrm{Mn}$ & $\mathrm{Pb}$ \\
\hline target & 2.68 & 60.56 & 21.72 & 13.21 & 1.60 & 0.23 \\
\hline as-grown & 3.07 & 60.13 & 20.16 & 14.85 & 1.78 & 0.02 \\
\hline $1000^{\circ} \mathrm{C}$ & 2.31 & 58.88 & 20.26 & 16.84 & 1.69 & 0.02 \\
\hline
\end{tabular}

The phosphor films were generally $300 \mathrm{~nm}$ to $400 \mathrm{~nm}$ thick as calibrated by a profiler. The XPS results showed that for all three kinds of phosphors, there is no change of the chemical state, and minor change of chemical composition for the target, the as grown and $1000^{\circ} \mathrm{C}$ annealed samples. Using 

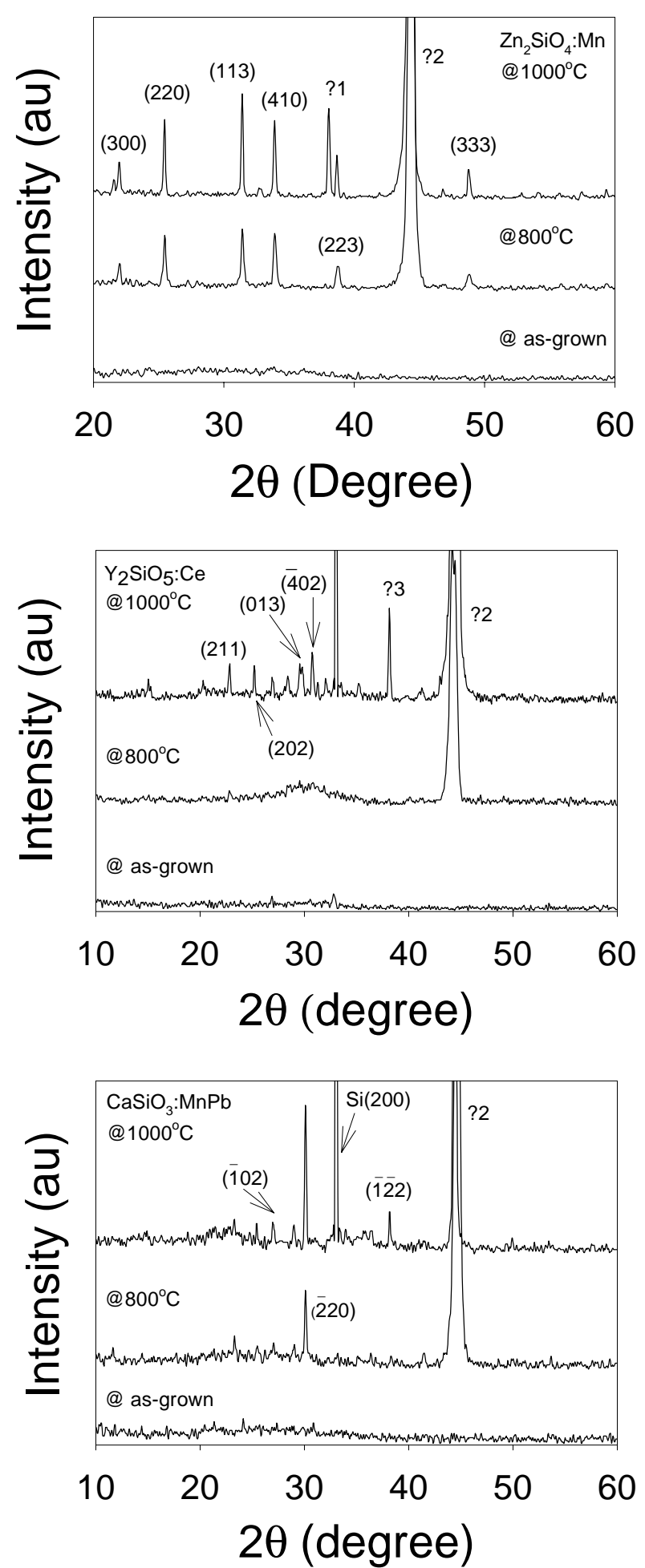

Fig 1. XRD $2 \theta-\theta$ scan of as-grown, $800^{\circ} \mathrm{C}$ and $1000^{\circ} \mathrm{C}$ annealed $\mathrm{Zn}_{2} \mathrm{SiO}_{4}: \mathrm{Mn}, \mathrm{Y}_{2} \mathrm{SiO}_{5}: \mathrm{Ce}$, and $\mathrm{CaSiO}_{3}: \mathrm{MnPb}$ films on $\mathrm{SiO}_{2} / \mathrm{Si}$ respectively (from top down).

$\mathrm{CaSiO}_{3}: \mathrm{MnPb}$ as an example, the elemental concentrations were shown in Table 1 . It can be seen that although the concentration of $\mathrm{Ca}, \mathrm{Si}$ and $\mathrm{O}$ deviate
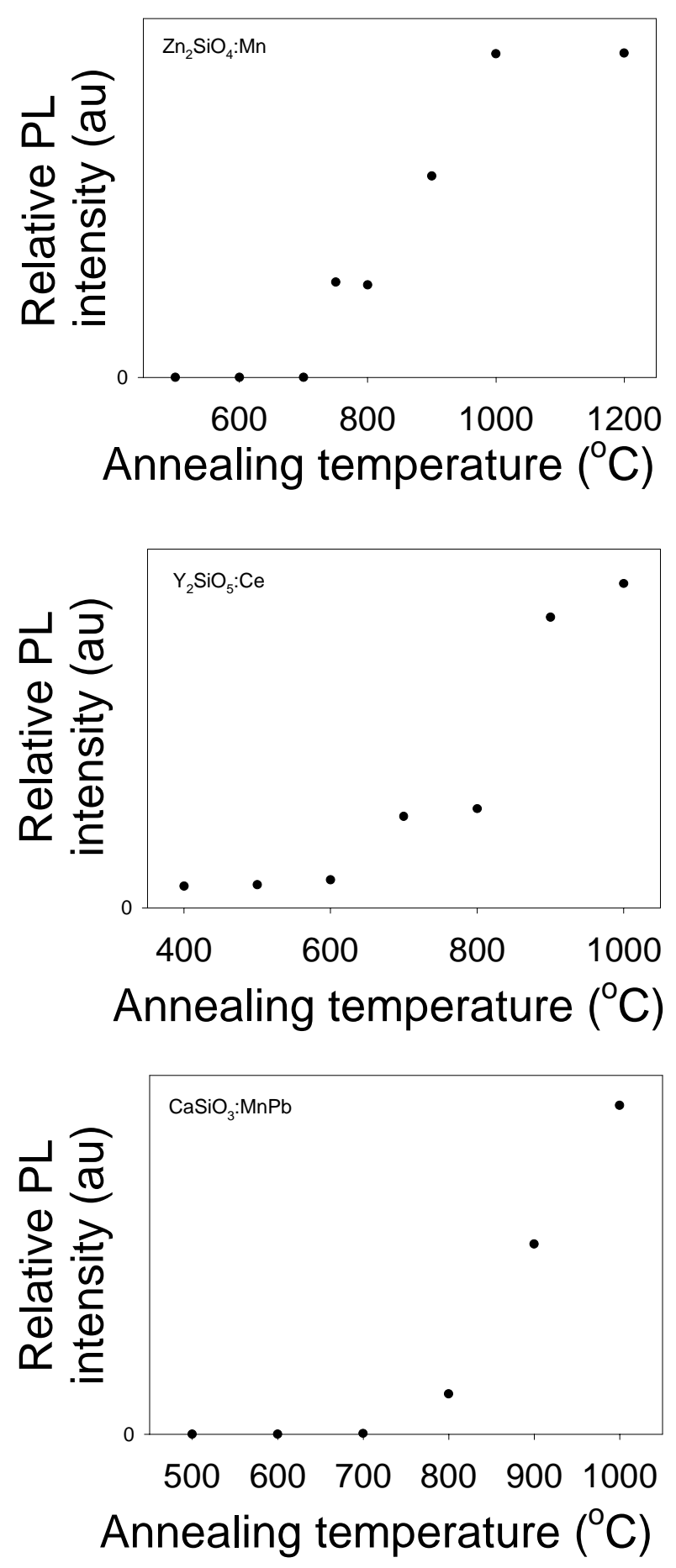

Fig 2. Relative PL intensity of $\mathrm{Zn}_{2} \mathrm{SiO}_{4}: \mathrm{Mn}, \mathrm{Y}_{2} \mathrm{SiO}_{5}: \mathrm{Ce}$, and $\mathrm{CaSiO}_{3}: \mathrm{MnPb}$ thin film as a function of annealing temperature respectively from top down.

from that of stoichiometric $\mathrm{CaSiO}_{3}$, which is acceptable for such a complex system, all the elements were well preserved as the target except $\mathrm{Pb}$. 

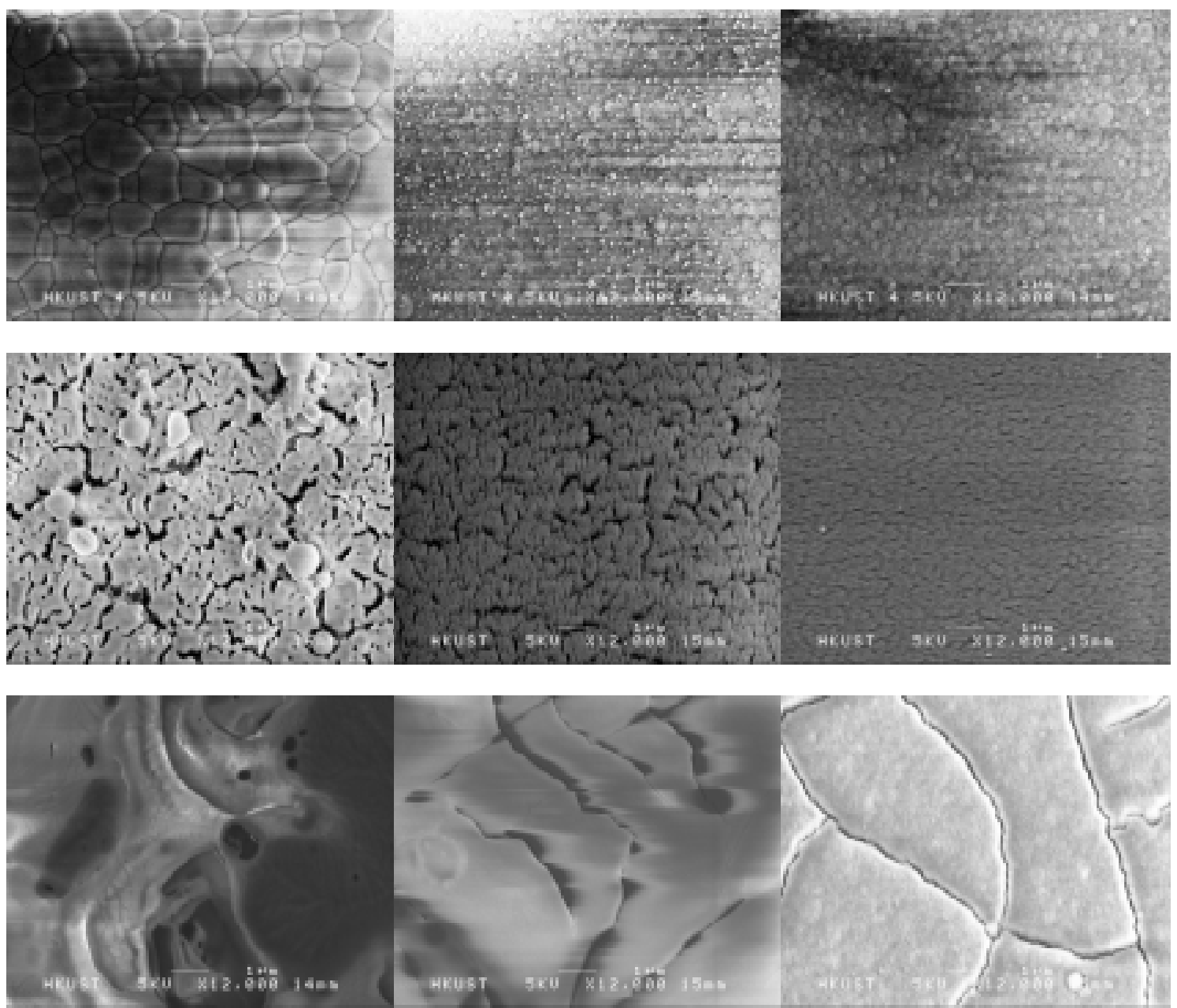

Fig $3 \mathrm{SEM}$ pictures of (from right to left ) as grown, $800^{\circ} \mathrm{C}$ and $1000^{\circ} \mathrm{C}$ annealed $\mathrm{Zn}_{2} \mathrm{SiO}_{4}: \mathrm{Mn}, \mathrm{Y}_{2} \mathrm{SiO}_{5}: \mathrm{Ce}$ and $\mathrm{CaSiO}_{3}: \mathrm{MnPb}$ (from top down) phosphor films respectively.

The XRD $\theta-2 \theta$ scans are shown in Fig 1 for the as-grown, $800^{\circ} \mathrm{C}$ and $1000^{\circ} \mathrm{C}(5$ hours in air) annealed $\mathrm{Zn}_{2} \mathrm{SiO}_{4}: \mathrm{Mn}, \mathrm{Y}_{2} \mathrm{SiO}_{5}: \mathrm{Ce}$, and $\mathrm{CaSiO}_{3}: \mathrm{MnPb}$ films grown on $\mathrm{SiO}_{2} / \mathrm{Si}$. Increasing crystallinity is clearly seen with increasing annealing temperature.

The PL intensity versus annealing temperature was depicted in Fig 2 for silicate phosphor thin films grown on $\mathrm{SiO}_{2} / \mathrm{Si}$ as a function of annealing temperature. There is no improvement of using bare $\mathrm{Si}$ substrate over $\mathrm{SiO}_{2} / \mathrm{Si}$ in terms of crystallinity from the $\mathrm{XRD}$ data. The as-grown and low temperature annealed $\mathrm{Zn}_{2} \mathrm{SiO}_{4}: \mathrm{Mn}$ and $\mathrm{CaSiO}_{3}: \mathrm{MnPb}$ films showed no photoluminescence. The as-grown $\mathrm{Y}_{2} \mathrm{SiO}_{5}$ : $\mathrm{Ce}$ film showed a weak photoluminescence. With postannealing at a temperature of $700^{\circ} \mathrm{C}$ or higher for 5 hours in air, the luminescent property improved significantly.

From Fig. 2, it can be seen that the photoluminescence of the annealed sample showed increasing PL intensity with annealing temperature from $800^{\circ} \mathrm{C}$ to $1000^{\circ} \mathrm{C}$, the PL intensity tends to saturate with further increase of the annealing temperature. The enhanced luminescence correlates well with the increasing crystallinity at increasing annealing temperature. The phosphor films deposited on $\mathrm{Si}$ substrate and $\mathrm{SiO}_{2} / \mathrm{Si}$ substrate showed comparable $\mathrm{PL}$ intensity after annealed, indicating that the luminescence is not sensitive to the substrate used.

SEM pictures of the samples are shown in Fig 3. The surface morphology of the phosphor films grown on $\mathrm{SiO}_{2} / \mathrm{Si}$ substrate resembles that of the film grown on Si. Note that the cracks on the SEM picture of the asgrown $\mathrm{CaSiO}_{3}: \mathrm{MnPb}$ sample is due to electron 


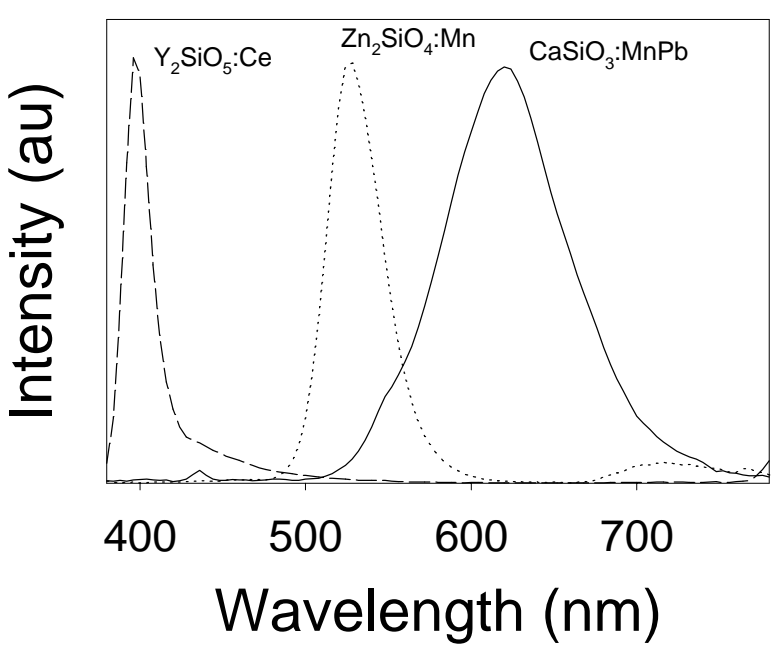

Fig $4 \mathrm{PL}$ spectra of red $\mathrm{CaSiO}_{3}: \mathrm{MnPb}$, green $\mathrm{Zn}_{2} \mathrm{SiO}_{4}: \mathrm{Mn}$ and blue $\mathrm{Y}_{2} \mathrm{SiO}_{5}: \mathrm{Ce}$ phosphor films grown by PLD.

beam induced peeling during SEM photographing. Combining the AFM data (not shown here) with the SEM results, it is inferred that the surface morphology does not change much with lower annealing temperature $\left(<800^{\circ} \mathrm{C}\right)$. However, with annealing temperatures higher than $800^{\circ} \mathrm{C}$, the surface becomes a little bit rough. The PL intensity as shown by Fig 2, experiences a sharp change at about $800^{\circ} \mathrm{C}$ for all three kinds of phosphors. So the enhanced luminescence is due to the increased crystallinity as well as better surface morphology. But the PL intensity, the film crystallinity and surface morphology are not sensitive to the substrate used.

Reasonably good purity RGB chromaticity is obtained from the $\mathrm{CaSiO}_{3}: \mathrm{MnPb}, \mathrm{Zn}_{2} \mathrm{SiO}_{4}: \mathrm{Mn}$, and $\mathrm{Y}_{2} \mathrm{SiO}_{5}$ :Ce films. Fig 4 shows the spectra measured with a Photo Research (model PR650) spectrometer. The PL of the $\mathrm{CaSiO}_{3}: \mathrm{MnPb}, \mathrm{Zn}_{2} \mathrm{SiO}_{4}: \mathrm{Mn}, \mathrm{Y}_{2} \mathrm{SiO}_{5}: \mathrm{Ce}$ films peak at $620 \mathrm{~nm}, 520 \mathrm{~nm}$ and $400 \mathrm{~nm}$ respectively. The red tail of $\mathrm{Zn}_{2} \mathrm{SiO}_{4}: \mathrm{Mn}$ (green) and $\mathrm{Y}_{2} \mathrm{SiO}_{5}: \mathrm{Ce}$ (blue) phorsphors come from the unfiltered light of the xenon lamp excitation source. The red emission spectrum of $\mathrm{CaSiO}_{3}: \mathrm{MnPb}$ thin film was measured with $193 \mathrm{~nm} \mathrm{ArF}$ laser excitation. The corresponding CIE chart is shown in Fig. 5.

\section{Conclusions}

In summary, RGB silicate phosphor thin films on both $\mathrm{Si}$ and $\mathrm{SiO}_{2} / \mathrm{Si}$ substrates were fabricated by pulsed laser deposition. Films deposited at $300^{\circ} \mathrm{C}$ substrate temperature showed no photoluminescence. Subsequent annealing at $800^{\circ} \mathrm{C}-1000^{\circ} \mathrm{C}$ in air produced

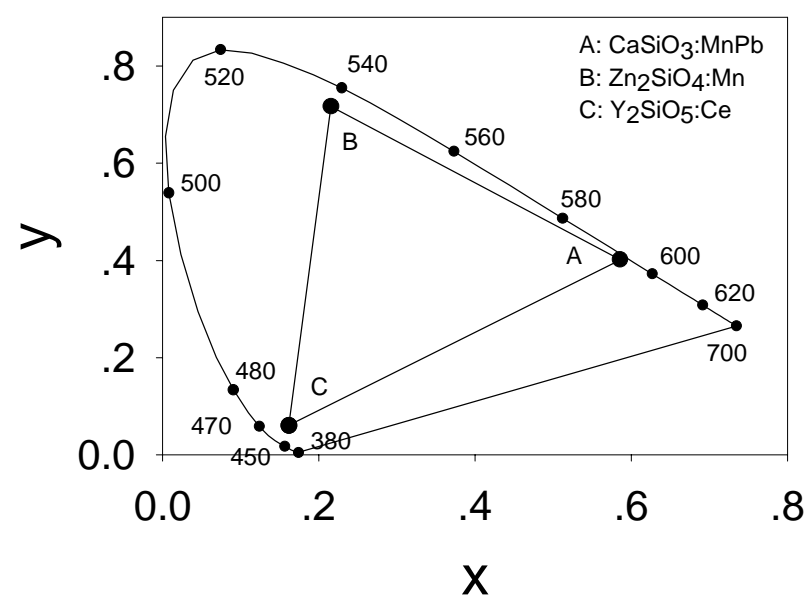

Fig 5 Chromaticity coordinates of the red $\mathrm{CaSiO}_{3}: \mathrm{MnPb}$, green $\mathrm{Zn}_{2} \mathrm{SiO}_{4}: \mathrm{Mn}$ and blue $\mathrm{Y}_{2} \mathrm{SiO}_{5}$ :Ce phosphor films grown by PLD.

strong red, green and blue photoluminescence for all three colors. It is expected that these silicate phosphor thin films should have applications in low voltage cathodoluminescence for field emission displays and in electroluminescence displays.

\section{References}

1. P. N. Yocom, J. of SID 4, 149 (1996).

2. T Minani, T Miyata, S Takata, and I Fududa, Jap. J Appl. Phys. 30, L117 (1990).

3. J. M. Robertson, Thin Solid Films 141, 221 (1984).

4. D. B. Chrisey, and G. K. Hubler, Pulsed Laser Deposition of Thin Films, John Wiley \& Sons, Inc. (1994).

5. M. McLaughlin, H. Sakeck, P. Macquire, W. Graham, J. Molloy, T. Morrow, S. Lavery, and J. Anderson, Appl. Phys. Lett. 63, 1865 (1993).

6. C. Karner, P. Maguire, J. McLaughlin, S. Laverty, W. G. Graham, T. Morrow, R. M. Bowman, Philosophical Magazine Letters 76, 111 (1997).

7. J. M. Siqueiros, J. A. Diaz, O. Contreras, G. A. Hirata, and J. McKittrick, Mater. Res. Soc. Symp. Proc. 397, 247 (1996).

8. J. Greer, H. Van Hook, M. Tabat, H. Nguyen, G. Gammie, and P. Koufopouls, Mater. Res. Soc. Symp. Proc. 345, 281 (1994).

9. S. L. Jones, D. Kumar, R. K. Singh, and P. H. Holloway, Appl. Phys. Lett. 71, 404 (1997).

10. X. Ouyang, A. H. Kitai, R. Siegele, Thin Solid Film 254, 268 (1995). 